\title{
Wind tunnel study of coal dust release from train wagons
}

\author{
A.D. Ferreira ${ }^{\mathrm{a}, *}$, P.A. Vaz ${ }^{\mathrm{b}}$ \\ ${ }^{a}$ Department of Mechanical Engineering, University of Coimbra, Polo II, 3030-290 Coimbra, Portugal \\ ${ }^{\mathrm{b}}$ Escola Superior de Tecnologia de Viseu, 3504 VISEU, Portugal
}

\begin{abstract}
The paper presents a wind tunnel study to assess the coal dust released due to aeolian erosion from wagons equipped with two different shelter cover systems. A 1:25 scale model was used, and it comprises one locomotive and four train wagons with a $3.55 \mathrm{~m}$ maximum length. Several tests were conducted for different train configurations, and two initial load levels, with an undisturbed flow velocity of $13.4 \mathrm{~m} / \mathrm{s}$.

Experiments show the use of covers reduces the amount of dust released to be less than $20 \%$ of the quantity eroded from the uncovered wagon. Results are primarily related to time series of released mass, for different conditions. Free-surface time evolution inside the last wagon is shown to illustrate marked differences by using the two distinct cover systems.
\end{abstract}

(C) 2004 Elsevier Ltd. All rights reserved.

Keywords: Coal; Solid pollutant; Train transportation; Dust release; Aeolian erosion

\section{Introduction}

In many developed countries coal is one of the main energy sources, either for heat generators furnaces or for electrical energy production in power plants. Coal is often extracted from mines located far away from the place where it will be used, and different transportation means are employed, however, the train represents the common one [1,2].

In terms of chemical composition coal does not represent any major dangerous pollutant but, as considerable coal dust quantities may be lost from train wagons due to aeolian erosion, they are capable of producing a considerable environmental

*Corresponding author. Tel.: 351-239-790-727; fax: 351-239-790-771.

E-mail address: almerindo.ferreira@dem.uc.pt (A.D. Ferreira). 
impact on some residential or agricultural areas, particularly those crossed by the railway or located near to it [3].

Many publications have addressed several coal issues, and in particular storage problems [4,5], but those devoted to the environmental impact issue due to train transportation, are very scarse.

This work results from the cooperation between ADAI (Association for the Development of Industrial Aerodynamics) and Tejo Energia, S.A., a company running a power plant consuming annually 1.5 million metric tons of coal. The power plant is located $350 \mathrm{~km}$ away from the port where the coal is unloaded from cargos. From a previous study [6], where some full-scale measurements were performed, the coal released due to Aeolian erosion was estimated to be roughly $0.0007 \%$ of the total load, a value considerably lower than those quoted in the literature $(0.05-1 \%)$ of the total load [7]. Tejo Energia, S.A. has a project for a new type of a cover system for the train cars but, before its adoption, the environmental impact and covers' effectiveness needed to be evaluated in what concerns the dust release.

Due to loading constraints and some other operational aspects, the size of the covers is restricted, and the full-cover is not an option. To compare the different results, tests must be conducted for similar conditions. The rationale for this wind tunnel study is the ability of conducting the tests under high repeatability conditions, allowing an unbias assessment of the covering system that is being proposed. It should be noted that results from full scale measurements for this study have a high uncertainty component, primarily because there is no assurance in what repeatability is concerned. The primary aim of this wind tunnel study is the quantification of the dust released and the effectiveness of the covering system. For the study it was used a 1:25 scale model reproducing one locomotive and four wagons.

Experimental results show time series of the coal weight released, and also the time-evolution of the free surface contour developed for the fourth wagon - the most critical, as it will be shown. The effectiveness of the covers is calculated based on the total amount of dust released.

The main objective of this study is focused on the comparison of the released coal for the wagons with and without covers, therefore, full-scale conditions are not required as the absolute values are not necessary.

\section{Experimental setup and procedure}

\subsection{Train model}

For the experimental simulation, a 1:25 scale model was constructed, reproducing with great detail one locomotive and four wagons. The geometry and full-scale dimensions of each car are shown in Fig. 1, where it can be seen that the maximum length and height of each actual car is approximately 17 and $4 \mathrm{~m}$, respectively $(0.68 \mathrm{~m} \times 0.16 \mathrm{~m}$ in the model). The maximum length of the composition, when the 


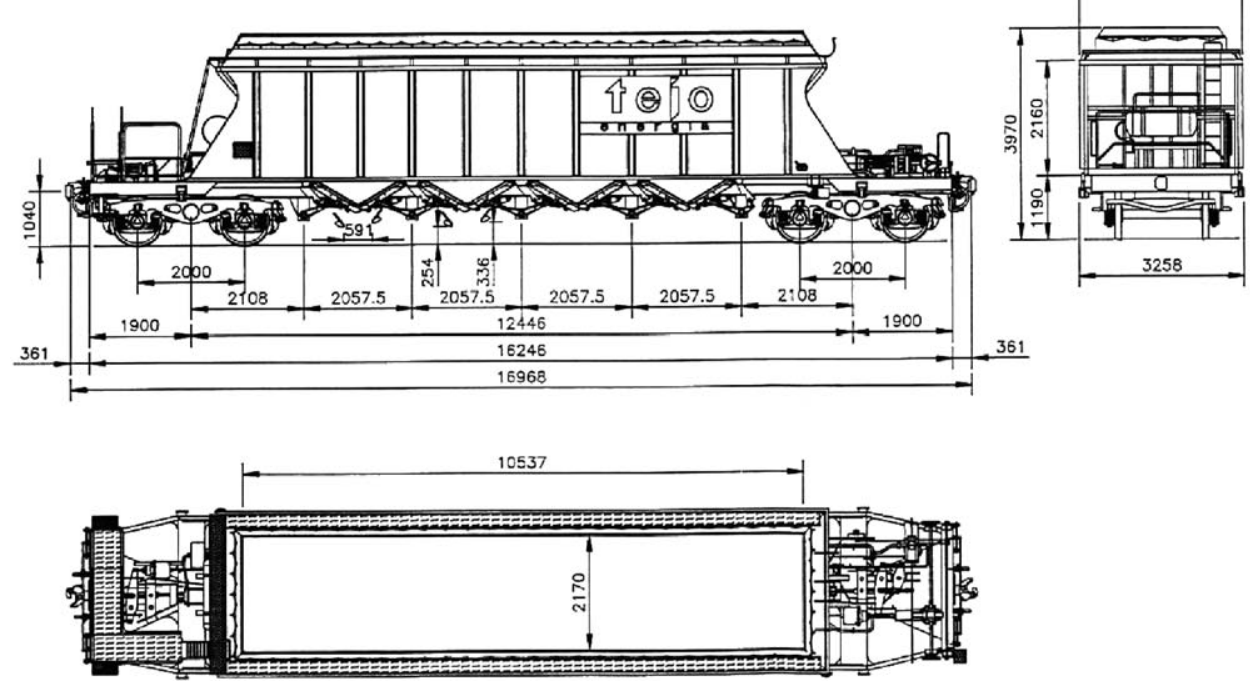

Fig. 1. Full-scale dimensions of the train cars modeled (dimensions in $\mathrm{mm}$ ).

locomotive and the four car models are placed in the wind tunnel working section, is $3.55 \mathrm{~m}$.

One model car had the top completely open $(10.54 \mathrm{~m} \times 2.17 \mathrm{~m}$ in full scale- see Fig. 1), while the other three cars were equipped with a "semi-cover" system partially covering the upper surface. The central gap, along the upper-part of all semi-covered full-scale wagons, is $1 \mathrm{~m}$ wide. For the sake of simplicity, hereafter, the open and "semi-covered" cars will be referred as "O" and "C" types, respectively.

\subsection{Wind tunnel and electronic balance}

The wind tunnel used for this study is installed at the Industrial Aerodynamics Laboratory (LAI), which is part of the ADAI facilities (University of Coimbra, Portugal). Is has an open working section, $5 \mathrm{~m}$ long and $2 \mathrm{~m}$ wide.

For the time characterization of the coal loss rate, it was used an electronic balance Kern 700, with a precision of $\pm 0.05 \mathrm{~g}$, connected to a computer. The sample rate was set to $1 \mathrm{~Hz}$ but, due to the flow turbulence, and consequent fluctuations induced on the measured weight, mean values of $30 \mathrm{~s}$ were adopted for the analysis. The balance was positioned $2.4 \mathrm{~m}$ downstream of the leading edge of the working chamber. As the position of the balance was unchanged during the tests, for the study of the different configurations the placement of the train was set according to each particular simulation. In this way, as the wind profile and turbulence intensity varied along the working length, any change from test to test of the flow conditions around the car under test was only a function of the upstream cars and locomotive. 


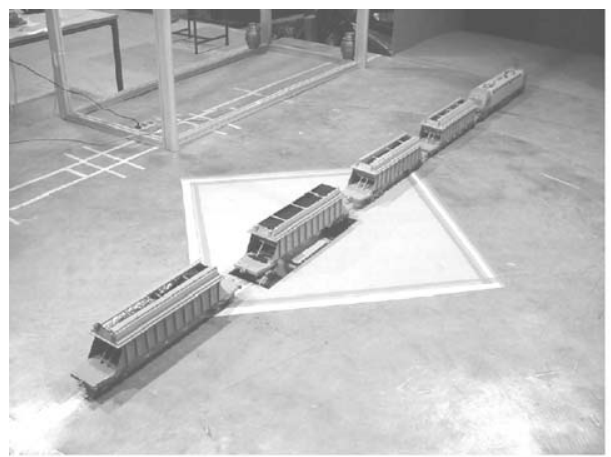

(a)

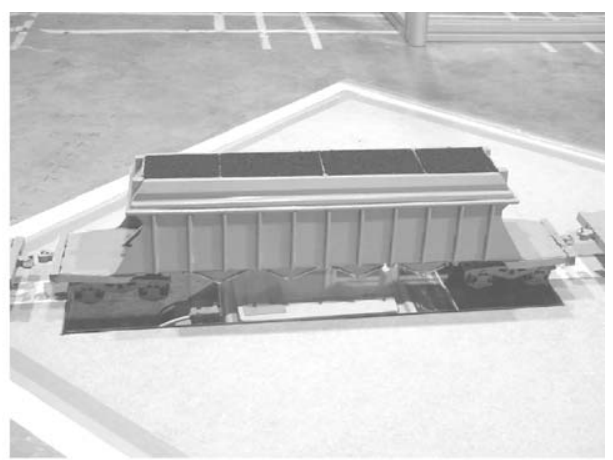

(b)

Fig. 2. Model in the working section for a $0^{\circ}$ flow incidence: (a) full view; (b) detailed view of the "open car" over the balance.

Fig. 2 shows the configuration, for which the complete model is placed in the wind tunnel working section (third composition wagon-O type-over the balance), and a close picture of the open car model located on the balance, both for a $0^{\circ}$ wind incidence angle.

The majority of the tests were conducted for an undisturbed velocity $\left(U_{0}\right)$ of $13.4 \mathrm{~m} / \mathrm{s}$. Some tests, performed at a lower velocity $\left(U_{0}=10.1 \mathrm{~m} / \mathrm{s}\right)$, showed no erosion of the coal particles used in the experiments, revealing a higher threshold wind speed than this for loss to occur.

\subsection{Experimental procedure}

As previously discussed, results from these tests are not intended to be directly extrapolated to the full-scale situation, as many different conditions would have to be satisfied, which would make the problem untractable using the present methodology .

To attain repeatability conditions particular care is required in what concerns the choice of the granulometry of coal to be used, the initial free-surface shape and load level, and as well as the definition of the different experimental phases. These items will be discussed in the following subsections.

\subsubsection{Coal granulometry}

The granular material used in the tests was filtered from the typical coal used by Tejo Energia, S.A. The coal used was the fraction that passed through a mesh (filter) $2 \times 2 \mathrm{~mm}^{2}$, which had the relative and cumulative granulometry distributions shown in Fig. 3. As expected, the maximum size of the grains is $2 \mathrm{~mm}$, while the most typical particles diameter ranges from $200-1100 \mu \mathrm{m}$. The reason for the choice of this maximum grains' size was based on threshold velocity values measured for different particles size samples. For larger particles' size, a higher velocity flow would be 


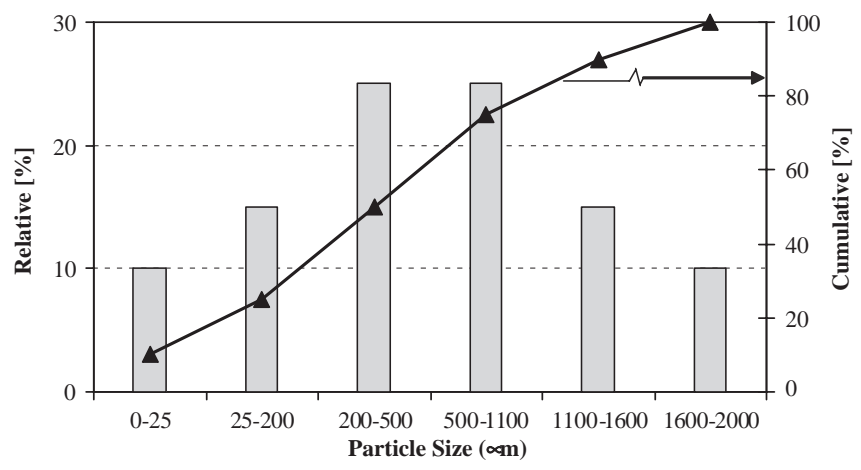

Fig. 3. Relative and cumulative granulometry distributions of the coal used in the tests.

needed to move the particles inside of the wagons. Furthermore, no scale buoyancy effects were taken into account when choosing the granulometry.

Before the wind tunnel tests, the granular material was placed on a drying stove at a temperature of $40^{\circ} \mathrm{C}$ for $12 \mathrm{~h}$ to lower its humidity, reducing the attractive forces between particles.

\subsubsection{Initial load levels}

In real conditions the free (upper) surface shape of the coal load inside the cars is irregular and varying in a random way. For the sake of repeatability condition, however, the free surface of the coal at the beginning of each laboratory test was levelled.

Two initial load levels were considered, one of them corresponding to the full load (N0 level), where the car was completely loaded, and the other one (N1 level) with the flat free-surface $0.01 \mathrm{~m}$ lower than the N0 level. These two levels comprise the mean full-scale level of a normal load if the coal at the beginning of its train transportation was levelled.

\subsubsection{Experimental phases}

The wind tunnel is equipped with a $230 \mathrm{kVA}$ electrical engine connected to a large fan. Due to inertia, some time is necessary before the steady-state velocity $\left(U_{0}=13.4 \mathrm{~m} / \mathrm{s}\right)$ is reached. Under this circumstances, the flow velocity varies during the first phase of the experimental tests. Nevertheless, as was experimentally observed and already mentioned, the erosion process is basically absent for undisturbed flow velocities below $10.1 \mathrm{~m} / \mathrm{s}$, and then most of the "erosion phase" might be considered to occur at the chosen test speed.

During a typical test the different experimental phases follow the schedule shown in Table 1. For most cases, the tests were stopped when the weight loss was becoming nearly constant. The time $3300 \mathrm{~s}$, Table 1, is just a typical value, and it was used for only a few tests. 
Table 1

Typical stages during an erosion test

\begin{tabular}{llll}
\hline Phase & Time $(\mathrm{s})$ & Procedure & Objective \\
\hline 1st & $0-200$ & Preliminary test actions & Balance reading control \\
2nd & $200-470$ & Wind tunnel acceleration & Increase of velocity until $U_{0}=13.4 \mathrm{~m} / \mathrm{s}$ \\
3rd & $470-3000^{\mathrm{a}}$ & Constant velocity $\left(U_{0}=13.4 \mathrm{~m} / \mathrm{s}\right)$ & Erosion phase \\
4 th & $3000^{\mathrm{a}}-3300^{\mathrm{a}}$ & Deceleration & Lift force abolishment \\
5th & $3300^{\mathrm{a}}-$ & End of the test $\left(U_{0}=0 \mathrm{~m} / \mathrm{s}\right)$ & Final loss evaluation \\
\hline
\end{tabular}

${ }^{\mathrm{a}}$ Variable value.

\section{Results}

In this section the results obtained from the experimental tests are presented. As already mentioned, only one electronic balance was used, so results refer to individual tests where just one car is monitored at a time. In this way, the collection of coal particles from upstream cars by the car under testing is not possible, as only the car being tested was loaded.

For the sake of simplicity, and taking into account that different configurations were simulated, the position of each wagon will be indicated by its covering type. The nomenclature used in this section obeys the following rules: open cars will be referred as "O", semi-covered as " $C$ ", being the corresponding character replaced by a "B" for the wagon placed over the balance. In a composition, as a locomotive (L) is tested always in conjunction with 4 wagons (one $\mathrm{O}$ and three $\mathrm{C}$ ), the sequence "LBCCC", e.g., corresponds to the case where the weight of the first car is being monitored and is of type " $\mathrm{O}$ ", while the remaining wagons, placed on the downstream positions, are all of the "semi-covered" type.

\subsection{Lift}

The flow around a non-symmetrical body induces net forces over it, as is well known. Similar phenomena do occur with the wagons, with the lift force (vertical) on each one of them being a function of its position in the composition. The lift-force is algebraically added to the force equivalent to the quantity of coal eroded (both vertical), affecting the immediate evaluation of the real amount released. Consequently, for the correct analysis of the results shown below, the lift component needs to be nullified, which is realized after the wind tunnel flow is stopped.

Table 2 indicates the lift forces on each wagon, for two undisturbed velocities and different positions of the wagon in the composition, and Fig. 4 shows the time variation of the lift force acting on a wagon type $\mathrm{O}$, for different configurations, as an example.

\subsection{Coal lost from one isolated wagon}

The first experiments were conducted for the case of one isolated wagon, which is a reference case. Both types of wagons ( $\mathrm{O}$ and $\mathrm{C}$ ) were tested, loaded with two 
Table 2

Lift force acting on a wagon as function of its placement on the composition and wind speed (in grams)

\begin{tabular}{llccccc}
\hline$U_{0}(\mathrm{~m} / \mathrm{s})$ & Wagon & Isolated & 1st pos. & 2nd pos. & 3rd pos. & 4th pos. \\
\hline 10.1 & O & 63 & 6 & 5 & 3 & 23 \\
& C & 66 & 7 & 7 & 11 & 28 \\
13.4 & & & & & 20 & 40 \\
& O & 115 & 10 & 12 & 17 & 50 \\
\hline
\end{tabular}

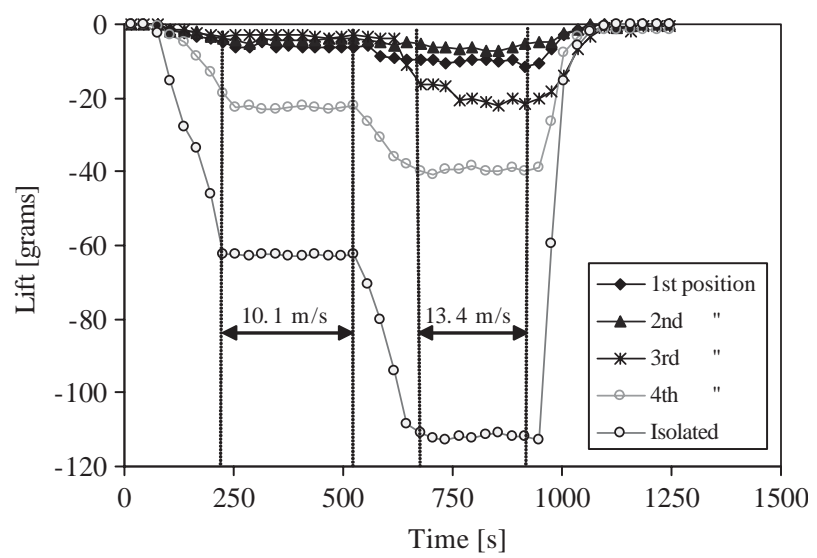

Fig. 4. Lift force acting on a wagon type "O", placed in different positions in the composition, for two wind tunnel undisturbed velocities (10.1 and $13.4 \mathrm{~m} / \mathrm{s}$ ).

different initial load levels, as mentioned before in Section 2.3.2. Fig. 5 shows the respective results and it can be seen that, at the end, when the lift effect becomes zero, the quantities lost are $85,120,285$ and $580 \mathrm{~g}$, for the different cases studied. This means that, for the $\mathrm{N} 0$ case, the proportional relation between the amounts lost are $1 \mathrm{~g}$ from wagon $\mathrm{C}$ to $4.8 \mathrm{~g}$ from the wagon $\mathrm{O}$, which means a reduction of $80 \%$ due to the use of semi-covers. For the N1 initial load level, the amount released from the $\mathrm{C}$ wagon is $70 \%$ smaller relatively to the $\mathrm{O}$ wagon.

When the analysis is made changing only the initial load levels, for the same type of covers, it can be seen that the quantities released in the N1 case, relatively to the N0 situation, from wagons $\mathrm{C}$ and $\mathrm{O}$, are $40 \%$ and $100 \%$ smaller, respectively.

\subsection{Coal lost from a wagon in a composition}

In the previous section it was treated the isolated wagon case, while this section deals with a more realistic situation, where several configurations obtained with the complete set of wagons will be analysed. Figs. 6 and 7 show the loss time-series from 


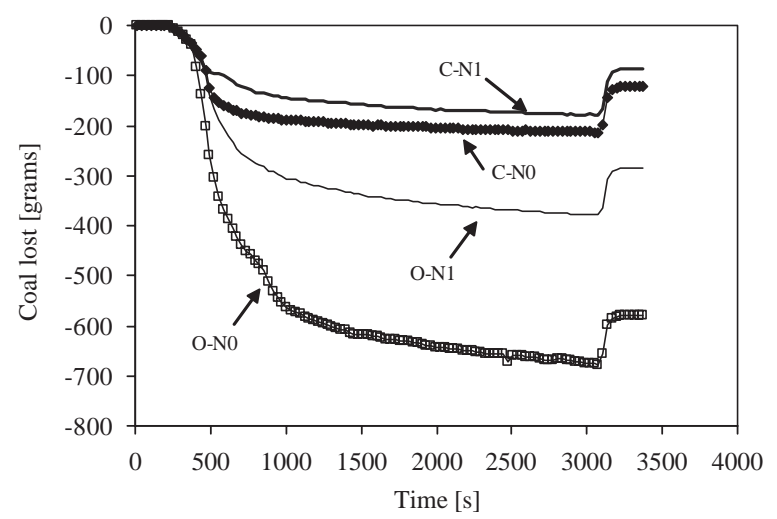

Fig. 5. Coal dust released for one isolated wagon, for two types of shelter covers ( $\mathrm{C}$ and $\mathrm{O})$ and two initial load levels (N0 and N1).

a wagon placed in the first (immediately after the locomotive), second, third and fourth position, respectively. Each figure contains the information for the two cover types and two initial load levels. Fig. 7(b) is the only one showing, at the end, the effective amount lost after the tunnel is stopped, except the "LCCOB-N0" case. For all the remaining cases compensation for the lift force needs to be made, according to Table 2. For example, while the final value shown in Fig. 7(a) is $-87 \mathrm{~g}$, the effective coal amount released was $76 \mathrm{~g}(-87+11)$.

From Figs. 6(a) and (b), and for the initial load level N1, it can be concluded that the coal amount released from $\mathrm{C}$ type cars is practically negligible. It can also be noticed, from Fig. 6(a) that the amount released from the $\mathrm{C}-\mathrm{N} 0$ situation (LBOCC$\mathrm{N} 0$ ) is similar to the O-N1 case (LBCCC-N1), which clearly shows that the semicovers produce an effective shelter effect.

By just observing the final released quantities, for experiments with equal initial load levels, the shelter effect due to the covers can be better assessed. Table 3 summarizes this analysis and reveals that the amount released from $\mathrm{C}$ wagons is significantly smaller comparatively to the $\mathrm{O}$ car, with particular emphasis on the wagons placed in middle positions, where the uncovered car loses approximately five times more coal than the covered wagon.

Cases $\mathrm{C}-\mathrm{N} 1$ and $\mathrm{O}-\mathrm{N} 1$, for the cars placed in the first and second positions, are not included in Table 3 as the quantity released from $\mathrm{C}$ cars is significantly smaller than that for the $\mathrm{O}$ wagon case, which would give rise to considerable larger weight-relation values than those shown in Table 3, as can be observed from Figs. 6(a) and (b).

As mentioned before, no extrapolation for estimating coal amounts released during a certain trip, using this data, can be made to the full-scale situation. Even so, from the results presented, the shelter effect that would be produced at full-scale by the adoption of the semi-covers can be estimated. To a first approximation, it can be said that the use of semi-covers, compared to the situation of cars with no cover system, would effectively reduce the environmental impact, lowering the amounts 

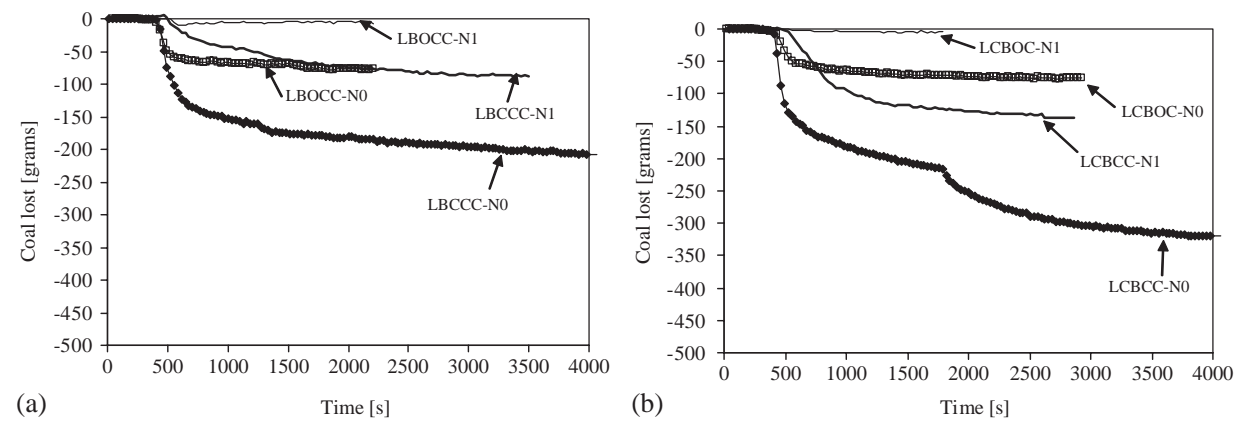

Fig. 6. Time series of coal amount released for a wagon placed: (a) on the first position and (b) second position, for two types of covers and two initial load levels.
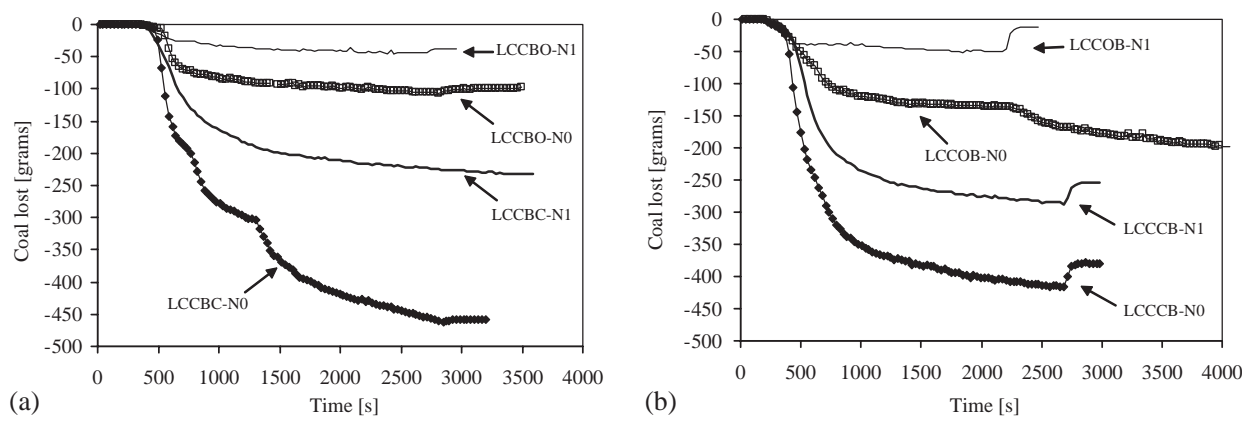

Fig. 7. Time series of coal amount released for a wagon placed: (a) on the third position and (b) fourth position, for two types of covers and two initial load levels.

Table 3

Relative quantities of coal released from wagons type $\mathrm{O}$ and $\mathrm{C}$

\begin{tabular}{lllll}
\hline Initial load level & C wagon & O wagon & Weight released C/O & Position \\
\hline N0 & LBOCC & LBCCC & $1: 2.5$ & 1 st \\
& LCBOC & LCBCC & $1: 4.7$ & 2 nd \\
& LCCBO & LCCBC & $1: 5.3$ & $3 \mathrm{rd}$ \\
& LCCOB & LCCCB & $1: 2.7$ & 4 th \\
N1 & & & 3 rd \\
& LCCBO & LCCBC & $1: 7.0$ & 4 th \\
\hline
\end{tabular}

${ }^{\text {a }}$ Relation defined at the end of the experiments.

released by a factor of 5, at least, as in reality the initial load level is always below the N0 situation.

Figs. 8 and 9 show the dependence of the amounts released as function of the car position in the composition. From those figures, it can be noticed that the amounts released increase significantly from the first to the last position for almost all the 

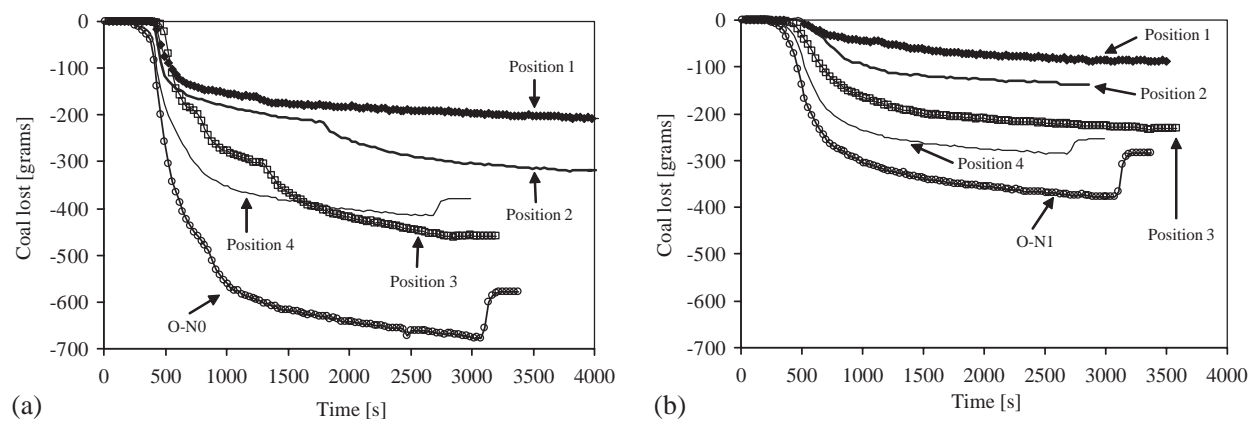

Fig. 8. Coal dust release from an open wagon $(\mathrm{O})$ placed in different positions, for two initial load levels: (a) N0; (b) N1.
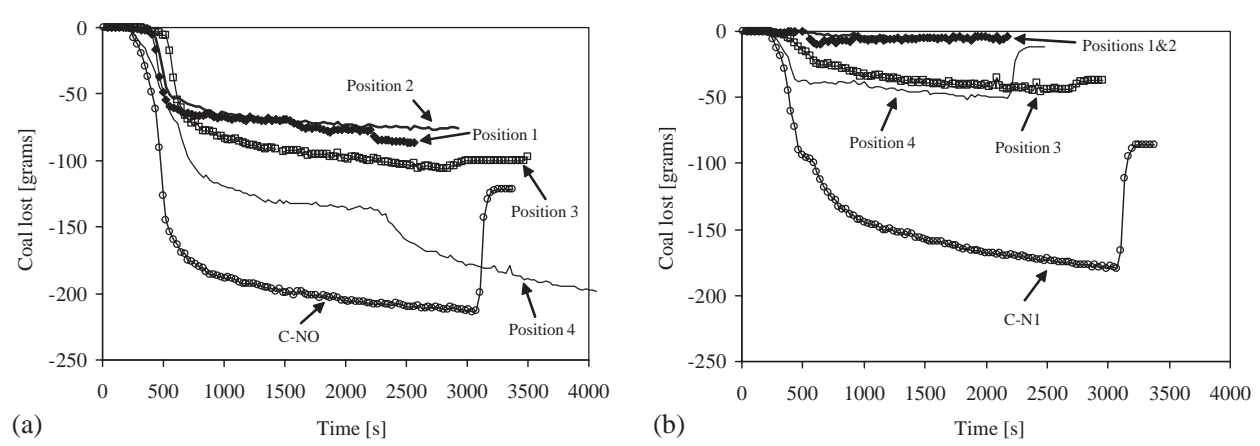

Fig. 9. Coal dust release from a semi-covered wagon (C) placed in different positions, for two initial load levels: (a) N0; (b) N1.

situations analysed, with the isolated car reaching the highest levels. This observation is very important, and it might be a good indication for the adoption of practical measures, namely the suggestion that the last two cars on a train composition should be completely covered when transporting granular material. The statement is also based on the results obtained for the isolated case; regarding at both and it seems that there is a tendency to increase the scour as downstream wagons are analysed. To further support this suggestion, new experiments are needed where more cars would be used - a line of research which was not possible to pursue in this work.

Fig. 10 shows, for the two different cars, and for the two loads, the time variation of the free-surface inside the fourth wagon, for which, as mentioned, the larger released amounts were observed in the composition. In the figure, the vertical scale is twice larger than the vertical one, and just the upper part of the wagons is represented, to enhance the details of the free-surface evolution. Yielding from the previous discussions, upper surface of the uncovered wagon shows the largest deformations, for both initial load levels. For the $(\mathrm{O}, \mathrm{N} 1)$ case, there is a first phase where the particles are displaced inside of the wagon to form two ramps, mainly 


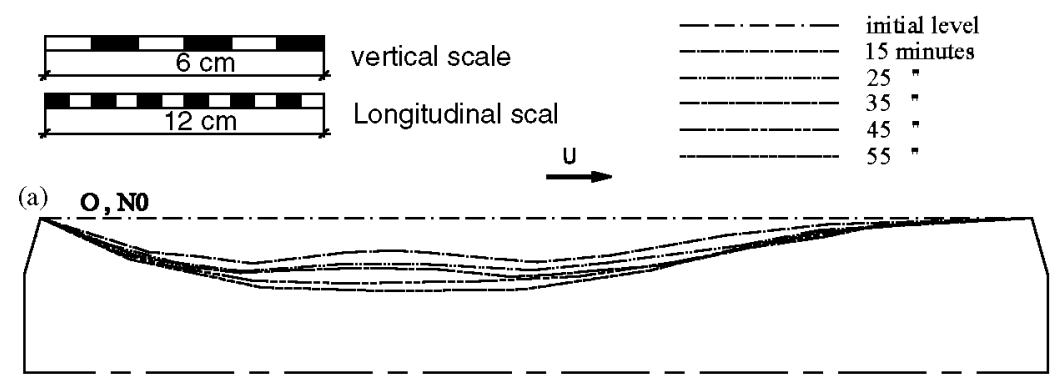

(b) $\mathrm{O}, \mathrm{N1}$

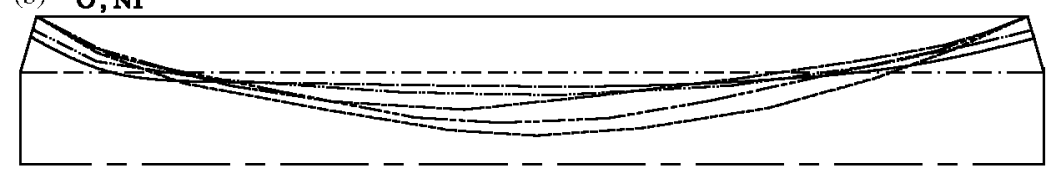

(c) $\mathrm{C}, \mathrm{NO}$

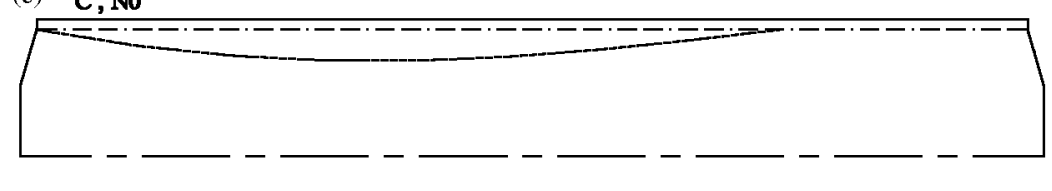

(d) $\mathbf{C}, \mathbf{N} 1$

Fig. 10. (a-d) Time variation of the free-surface inside the fourth wagon, for different cover systems and initial load levels.

through the rolling phenomena, as observed experimentally after video images analysis, the heaviest particles are rolled out, while the lightest particles exit mainly through flotation after being lifted up by the flow [8,9]. Also, as seen before, the loss from $\mathrm{C}$ wagon is considerably smaller for the $\mathrm{N} 1$ situation than for the N0 situation.

\section{Conclusions}

A wind tunnel study was presented, with the objective of giving a physical insight into the problem of coal dust release due to aeolian erosion during train transportation. A shelter-cover system, partially covering the upper part of the wagon, was tested and compared against the wagon with no covers.

Two initial load levels were simulated, one of them corresponding to the full load and the other one reproducing the reality of common practice.

The use of the semi-cover system, despite the existence of a one metre wide gap along the upper part of the wagon, significantly reduces the amount of dust released 
and, consequently, the potentially damaging environmental impact. Compared to the no-cover situation, the semi-cover reduces the dust amount released more than $80 \%$ for the full-load situation, being this value more expressive in situations for initial low load levels.

Analysing the release in terms of position of the wagons in the composition, the results for the last two wagons showed considerably larger quantities being eroded, suggesting the benefit of covering the last two cars in a composition during train transportation of granular material. As mentioned at the proper section, this suggestion needs further experiments to be fully supported.

This experimental work is part of a research project which also includes the development of numerical models aiming the computational simulation of this problem [10], for which part of the experimental data is being used for benchmarking.

\section{Acknowledgements}

The construction of the physical model was possible due to the expeditious effort and great skill of Mr. Alberto C.A. Santos. The cooperation received from Tejo Energia, S.A., and in particular from Eng. António Lopes da Silva, Director of Operations, is gratefully acknowledged.

Prof. A.C.M. Sousa, from the University of New Brunswick-Canada, gave a great contribution to this work, through continuous and very profitable discussions with the first author, and suggestions for the ongoing experimental research.

This work was funded by FCT (Science and Technology Foundation of Portugal) (Project POCTI/33512/EME/2000) with funds from the European Community through the FEDER Program.

\section{References}

[1] T.F. Edgar, Coal Processing and Pollution Control, Gulf Publishing Company, Houston, Texas, 1983 p.579.

[2] I.H. Knoepfel, A framework for environmental impact assessment of long-distance energy transport systems, Energy 21 (1996) 693-702.

[3] J.K. Lazo, K. McClain, Community perceptions, environmental impacts, and energy policy: rail shipment of coal, Energy Policy 24 (1996) 531-540.

[4] S.-J. Lee, C.-W. Park, The shelter effect of porous wind fences on coal piles in POSCO open storage yard, J. Wind Eng. Ind. Aerodyn. 84 (2000) 101-118.

[5] J. Xuan, A. Robins, Effects of turbulence and complex terrain on dust emissions and depositions from coal stockpiles, Atmos. Environ. 28 (1994) 1951-1960.

[6] A.D. Ferreira, D.X. Viegas, A.C.M. Sousa, Full-scale measurements for evaluation of coal dust release from train wagons with two different shelter covers, J. Wind Eng. Ind. Aerodyn. 91 (2003) 1271-1283.

[7] OECD, Coal-Environmental issues and remedies, Organisation for Economic Co-Operation and Development, 1983, p. 87. 
[8] P. Nalpanis, J.C.R. Hunt, C.F. Barrett, Saltating particles over flat beds, J. Fluid Mech. 251 (1993) 661-685.

[9] K. Nishimura, J.C.R. Hunt, Saltation and incipient suspension above a flat particle bed below a turbulent boundary layer, J. Fluid Mech. 417 (2000) 77-102.

[10] A.G. Gerber, S. Ji, A.D. Ferreira, A.C.M. Sousa, Particle dispersion modelling using an algebraic slip model with moving grids, in: Chien Wei-Zang et al. (Eds.), Proceedings of the 4th International Conference on Nonlinear Mechanics, Shanghai, Shanghai University Press, Shanghai, China, August 2002, pp. $778-783$. 